\title{
BEHAVIOR OF HIGH STRENGTH CONCRETE FILLED SQUARE STEEL TUBULAR COLUMNS WITH INNER CFRP CIRCULAR TUBE UNDER BI-AXIAL ECCENTRIC LOADING
}

\author{
G.C. Li ${ }^{1, *}$, Z.J. Yang ${ }^{2}$, Y. Lang ${ }^{3}$ and C. Fang ${ }^{1}$ \\ ${ }^{1}$ School of Civil Engineering, Shenyang Jianzhu University, Shenyang, 110168, China \\ ${ }^{2}$ School of civil Engineering, Tianjin University, Tianjin, 300072, China \\ ${ }^{3}$ Department of building Engineering, Suqian College, Jiangsu Province, 223800, China \\ *(Corresponding author: E-mail: cegcli@sjzu.edu.cn)
}

Received: 16 January 2012; Revised: 18 May 2012; Accepted: 22 May 2012

\begin{abstract}
This paper presents a theoretical study of high strength concrete filled square steel tubular columns with inner CFRP (carbon fiber-reinforced polymer) circular tube subjected to bi-axial eccentric loading. The new type of composite member is composed of a CFRP inner tube and a outer steel tube with concrete filled in the two tubes. The finite element analysis (FEA) is made by ABAQUS software on the behavior of high strength concrete filled square steel tubular columns with inner CFRP circular tube subjected to bi-axial eccentric loading. The results obtained from the finite element analysis were verified with the experimental results. An extensive parametric study was conducted to investigate the effects of steel yielding strength, concrete strength, steel ratio, slenderness ratio on the interaction curve $N / N_{u}-M / M_{u}$ of column subjected to bi-axial eccentric loading. The parametric studies provide information for the development of formula to calculate the bearing capacity. The experimental failure load and the predicted failure load calculated by the formula showed good agreement.
\end{abstract}

Keywords: CFRP tube, Square steel tube, High strength concrete, Bi-axial eccentric load, Finite element analysis (FEA)

\section{INTRODUCTION}

Concrete-filled square steel tubular (CFST) column has a higher bearing capacity, better ductility performance and fatigue resistance than common reinforced concrete and hollow steel section columns. And it also has some unique characteristics: (1) the simple type of beam-to-column connection, (2) the flexible building layout, (3) the stable behavior with large cross-section moment of inertia, (4) convenient construction. In recent, CFST were used widely in modern civil engineering, especially in high-rise buildings. Taipei 101, a 508-m high office tower, used rectangular columns with a maximum cross-sectional dimension of $2400 \mathrm{~mm} \times 3000 \mathrm{~mm}$, and finally the section of the column was reduced to $1600 \mathrm{~mm} \times 2000 \mathrm{~mm}$ [1]. Hangzhou Ruifeng commercial building was a 24-storey building with the height $88.2 \mathrm{~m}$, and the maximum section of $600 \times 600 \mathrm{~mm}$ CFST column was used in the structure.

Many research projects have been conducted in the past few decades to investigate the behaviors of CFST columns subjected to axial compression and concentric load (Dalin Liu (2003, 2004, 2006) [2-4], Ehab Ellobody[5-6], F.W. Lu (2007) [7], Manojkumar V(2010)[8], Han. ect ( 2001, 2002 ) [9-10], Mursi and Uy $(2001,2003,2004)$ [11-13]. It is well known that concrete-filled steel tubes, such as the columns (particularly at corners) of a tall building under horizontal wind or earthquake, may be subjected to bi-axial bending in practice. At present, the researches about column under bi-axial eccentric loading are seldom. Mursi and Uy have presented experimental and theoretical studies of fabricated high strength steel tubular columns subjected to biaxial bending [14-15]. Jie-Peng Liu and Hua Tian illustrated the pertinence relation for the three-dimensional bearing capacity of the members and presented the simplified formula [16-17]. Tokgoz, S reported the test results of 16 concrete-filled steel tubular columns subjected to bi-axial bending and short-term axial loading [18]. 
The concrete filled square steel tubular column with inner CFRP circular tube is composed of a CFRP inner tube, a outer steel tube, and concrete filled in the two tubes, as shown in Figure 1. In order to study the mechanical behavior of high strength concrete filled square steel tubular columns with inner CFRP circular tube (HCFSTF), the test of HCFSTF subjected to bi-axial eccentric loading has been done. The specimens finally quit working owing to the unstable failure [19]. FEA on HCFSTF subjected to bi-axial eccentric loading is presented in this paper. The calculating results of the model show good agreement with testing results.

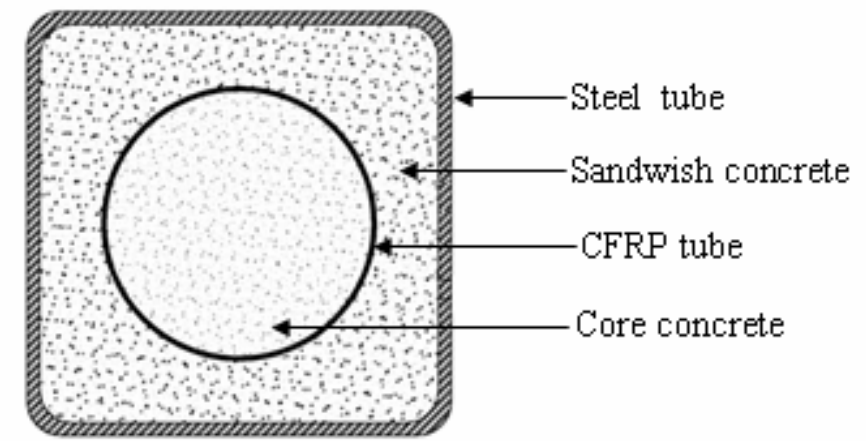

Figure 1. Cross Section of CFST with Inner CFRP Tube

\section{FINITE ELEMENT ANALYSIS}

\subsection{Material Constitutive Model}

\subsubsection{Steel}

The elastic-plastic behavior provided by ABAQUS was used to describe the constitutive behavior of the steel. Since cold-formed steel tubes were used in the test, different strengths and residual stresses in the corner zone and the flat zone should be considered. Therefore, an idealized multi-linear stress-strain model (as shown in Figure 2), which was developed by Abdel-Rahman and Sivakumaran [20], was adopted in this analysis. The first part of the multi-linear curve represents the elastic part up to the proportional limit stress with Young's modulus $E_{s}=206 \mathrm{GPa}$, and Poisson's ratio $(v)$ was taken as 0.3 .

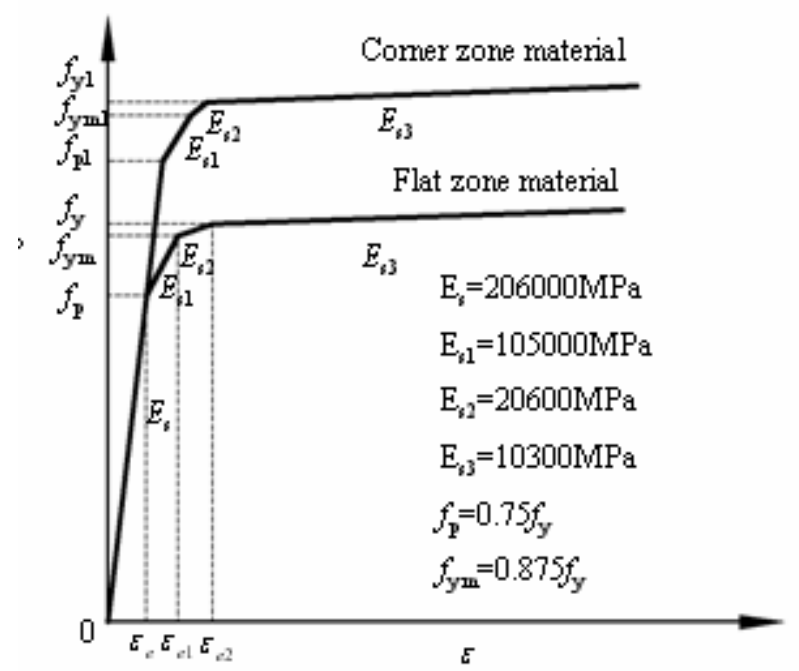

Figure 2. Idealized Stress-strain Relationships for Cold-formed Steel 


\subsubsection{Concrete}

The damaged plastic model provided by the ABAQUS library was adopted to simulate the concrete. Considering the concrete was confined by steel tube and CFRP tube, the stress-strain relationship of the core concrete proposed by Han was applied for ABAQUS finite element analysis [21]. The fracture energy-crack displacement model was used to emulate the tension stress-strain of concrete [22].

\subsubsection{FRP}

To reduce these possible complexities, the CFRP was assumed to be a linear elastic material. The CFRP confinement was also linear elastic. When the confinement reached its maximum fracture strength, the CFRP confinement was removed from the analysis. The specific expression is as follows:

$$
\begin{array}{ll}
\varepsilon \leq \varepsilon_{\mathrm{f}}, & \sigma_{\mathrm{f}}=E_{\mathrm{f}} \varepsilon \\
\varepsilon>\varepsilon_{\mathrm{f}}, & \sigma_{\mathrm{f}}=0
\end{array}
$$

Where $\sigma_{\mathrm{f}}$ is the ultimate stress of the fiber, $E_{\mathrm{f}}$ is the modulus of elasticity, $\varepsilon_{\mathrm{f}}$ is the ultimate strain.

\section{$2.2 \quad$ Finite Element Model}

The steel tube and concrete were modeled with 8-node brick elements (C3D8R), and a quad-node first-order reduced integration shell element (S4R) was chosen for CFRP tube. In order to simplify the problem and to reduce computational effort, only one quarter of the specimen was modeled in the analysis due to symmetry. Symmetric boundary conditions were enforced on the symmetric planes which were XSYMM and ZSYMM boundary conditions, shown in Figures 2. The meshes of the finite element models are shown in Figures 3. The nonlinear calculation exerted by displacement control was easier to be convergent. The incremental iterative method was used to solve nonlinear equations. More details of the FEA modeling can be found in the reference [19].

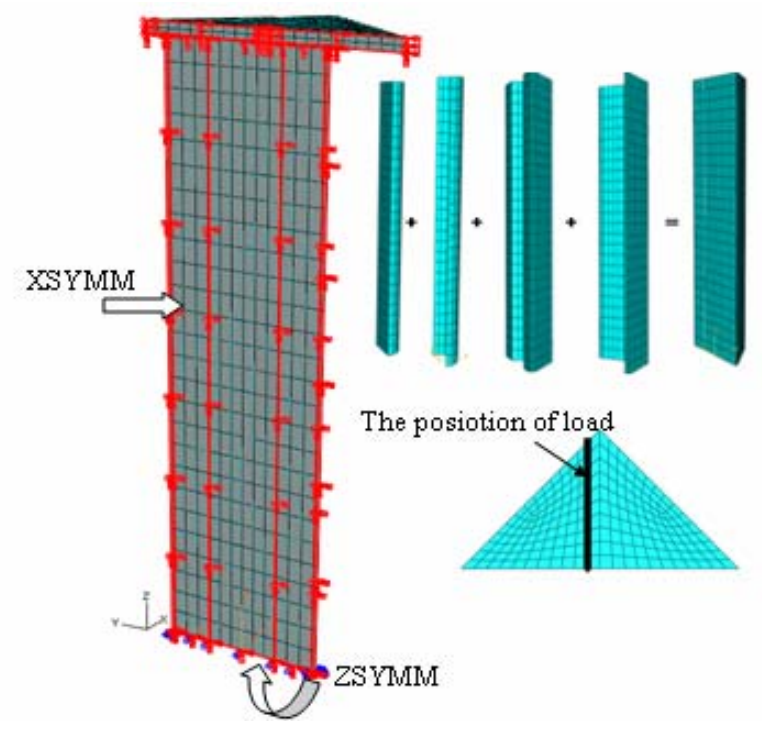

Figure 3. Boundary Condition of Analytical Model 
The FEA model established through the ABAQUS/Standard solver was used to simulate the concrete-filled square steel tube column with inner circular CFRP tube subjected to bi-axial eccentric loading. Table 1 shows the full details of the specimens and the comparisons between the finite element results and the experimental results. The average ratio of $M_{c 1} / M_{e}$ is 1.018 and the standard deviation is 0.073. It can be seen that the experimental results math the numerical modeling results well. Where $t_{s}$ is nominal thickness of steel tube; $t_{c}$ is measured thickness of CFRP tube; $f_{y}$ is yield strength of steel; $f_{C F R P}$ is ultimate tensile strength of CFRP; $e_{x}, e_{y}$ is the eccentricity along $\mathrm{x}$ and y axis; $N_{e}$ is the ultimate load of experimental result, $N_{c l}$ is the ultimate load of finite element calculation, and $N_{c 2}$ is the ultimate load of the simplified formula calculation.

\subsection{Load-deflection Relationship of Columns}

The predicted curves of load versus the lateral deflection at the mid-height of the columns are verified with the experimental data in Figures 4. The numerical results show a good agreement with the experimental data. As the Figures 4 shown, after the ultimate load, when the load declined to $80 \%$ of the ultimate load, the bearing capacity sharply declined because the CFRP at the mid-height of the columns reached the ultimate load, which caused the constraint deprivation of the core concrete. In addition, the numerical results and the experimental data in Figures 3 (b), (g), (h) do not match well at the last phase of the curves because local buckling is occurred at the end of specimens after the peak load.

Table 1. Test Results and Calculation Results

\begin{tabular}{cccccccccccc}
\hline Specimen & $\begin{array}{c}t_{s} \\
(\mathrm{~mm})\end{array}$ & $\begin{array}{c}f_{y} \\
(\mathrm{MPa})\end{array}$ & $\begin{array}{c}f_{u} \\
(\mathrm{MPa})\end{array}$ & $\begin{array}{c}t_{c} \\
(\mathrm{~mm})\end{array}$ & $\begin{array}{c}f_{C F R P} \\
(\mathrm{MPa})\end{array}$ & $\begin{array}{c}e_{x}=e_{y} \\
(\mathrm{~mm})\end{array}$ & $\begin{array}{c}N_{e} \\
(\mathrm{kN})\end{array}$ & $\begin{array}{c}N_{c 1} \\
(\mathrm{kN})\end{array}$ & $\begin{array}{c}N_{c 2} \\
(\mathrm{kN})\end{array}$ & $N_{c 1} / N_{e}$ & $N_{c 2} / N_{e}$ \\
\hline ESF4-5-28 & 4.5 & 291 & 79.7 & 0.334 & 3718 & 20 & 2483 & 2602 & 2793 & 1.048 & 1.125 \\
ESF4-5-71 & 4.5 & 291 & 79.7 & 0.334 & 3718 & 50 & 1761 & 1774 & 1608 & 1.008 & 0.914 \\
ESF4-5-113 & 4.5 & 291 & 79.7 & 0.334 & 3718 & 70 & 1063 & 1266 & 1155 & 1.191 & 1.086 \\
ESF6-5-28 & 4.5 & 291 & 79.7 & 0.334 & 3718 & 20 & 2618 & 2566 & 2731 & 0.980 & 1.043 \\
ESF6-5-71 & 4.5 & 291 & 79.7 & 0.334 & 3718 & 50 & 1463 & 1526 & 1559 & 1.043 & 1.065 \\
ESF6-5-113 & 4.5 & 291 & 79.7 & 0.334 & 3718 & 70 & 1146 & 1150 & 1109 & 1.002 & 0.967 \\
ESF8-5-28 & 4.5 & 291 & 79.7 & 0.334 & 3718 & 20 & 2417 & 2413 & 2661 & 0.998 & 1.101 \\
ESF8-5-71 & 4.5 & 291 & 79.7 & 0.334 & 3718 & 50 & 1508 & 1541 & 1454 & 1.022 & 0.965 \\
ESF8-5-113 & 4.5 & 291 & 79.7 & 0.334 & 3718 & 70 & 1022 & 1064 & 1058 & 1.040 & 1.035 \\
ESF10-5-28 & 4.5 & 291 & 79.7 & 0.334 & 3718 & 20 & 2346 & 2326 & 2586 & 0.992 & 1.102 \\
ESF10-5-71 & 4.5 & 291 & 79.7 & 0.334 & 3718 & 50 & 1477 & 1362 & 1356 & 0.922 & 0.918 \\
ESF10-5-113 & 4.5 & 291 & 79.7 & 0.334 & 3718 & 70 & 1004 & 957 & 1007 & 0.953 & 1.003 \\
ES4-4-71 & 3.5 & 306 & 79.7 & 0 & -- & 50 & 1524 & 1637 & 1501 & 1.074 & 0.985 \\
ES4-6-71 & 5.8 & 333 & 79.7 & 0 & -- & 50 & 1896 & 1899 & 1828 & 1.002 & 0.964 \\
ES6-4-71 & 3.5 & 306 & 79.7 & 0 & -- & 50 & 1548 & 1546 & 1406 & 0.999 & 0.908 \\
ES6-6-71 & 5.8 & 333 & 79.7 & 0 & -- & 50 & 1845 & 1818 & 1723 & 0.986 & 0.934 \\
ES8-4-71 & 3.5 & 306 & 79.7 & 0 & -- & 50 & 1517 & 1455 & 1314 & 0.959 & 0.867 \\
ES8-6-71 & 5.8 & 333 & 79.7 & 0 & -- & 50 & 1717 & 1738 & 1619 & 1.012 & 0.943 \\
\hline
\end{tabular}

The specimen type (for example:ESF4-5-28) in Table 1 is labeled as follows: letter E stands for specimen subjected to bi-axial eccentric loading; S stands for steel; F stands for FRP; 4 stands for ratio of specimen length to size of section side, $L / B=4,6,8,10$; next $5,4,6$ stands for the thickness of steel tube respectively in $\mathrm{mm} ; 28,71,113$ stands for eccentricity respectively in mm.. 


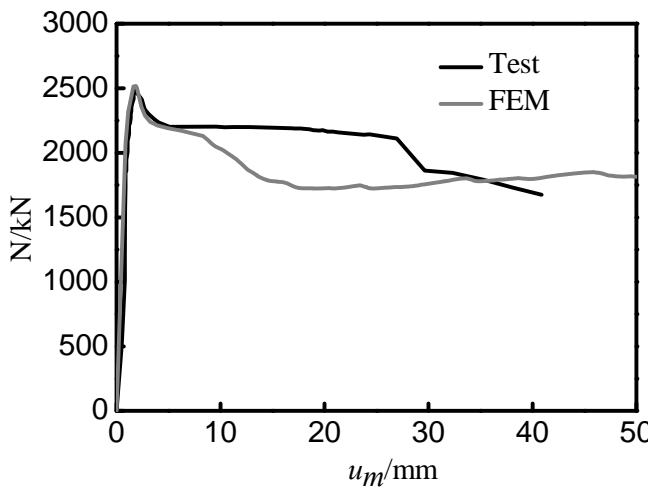

(a) ESF4-5-28

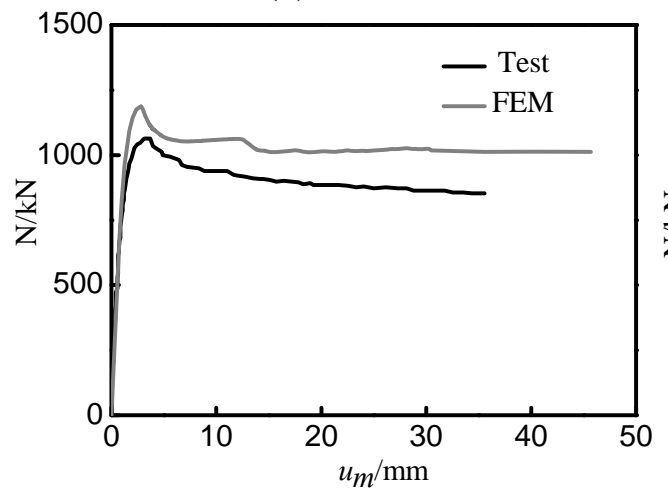

(c) ESF4-5-113

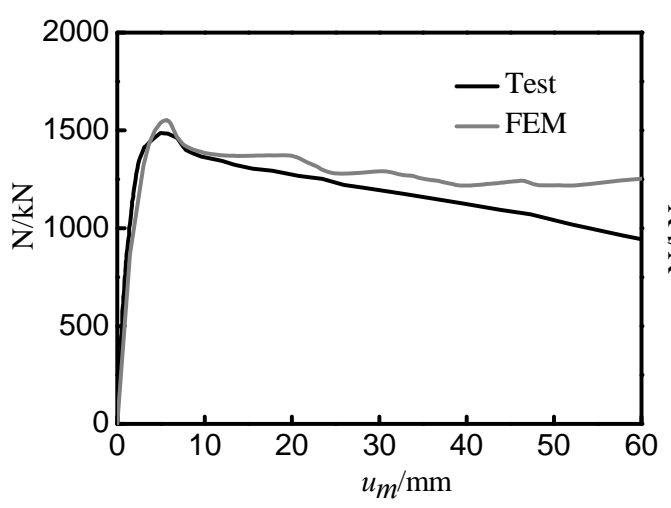

(e) ESF6-5-71

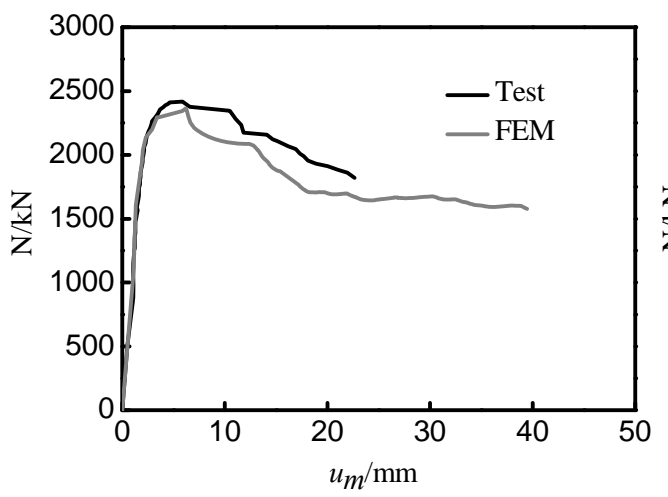

(g) ESF8-5-28

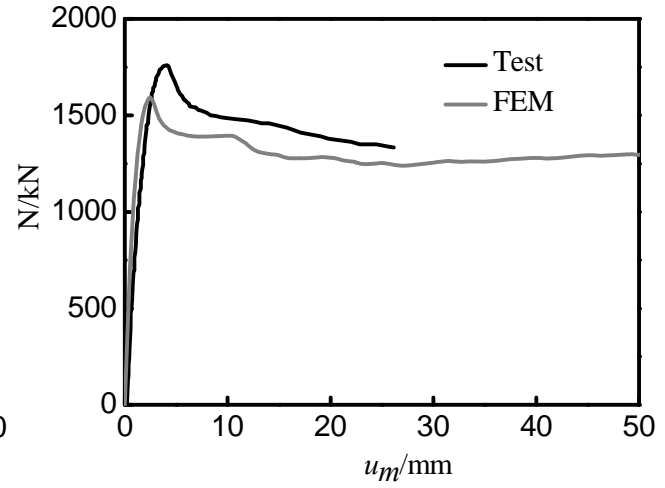

(b) ESF4-5-71

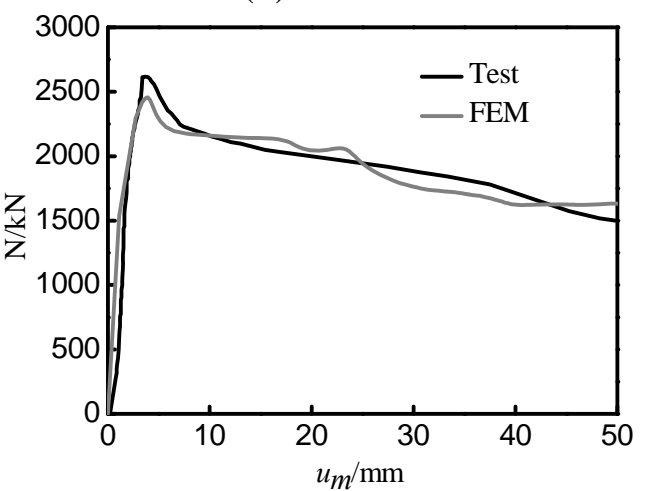

(d) ESF6-5-28

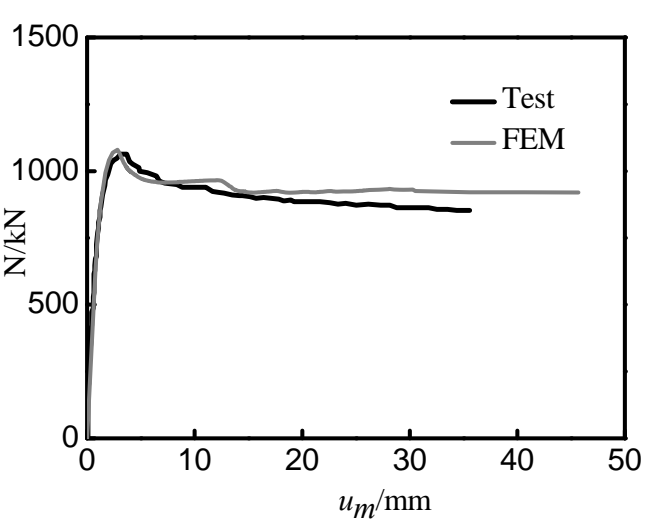

(f) ESF6-5-113

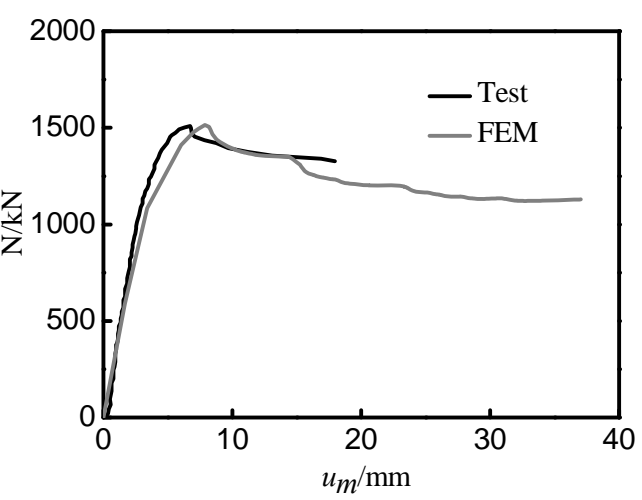

(h) ESF8-5-71 


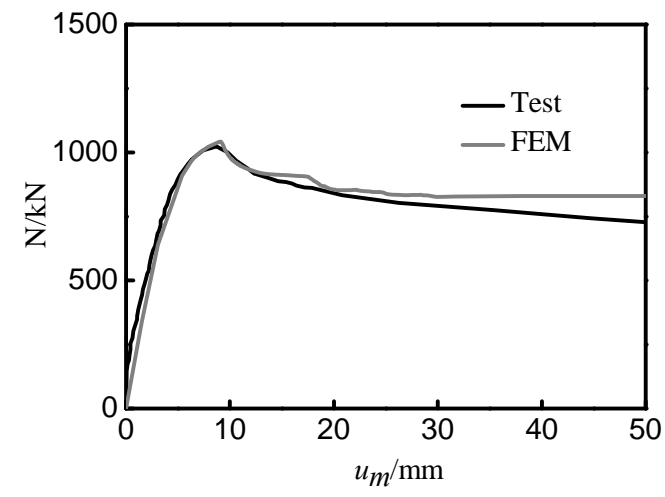

(i) ESF8-5-113

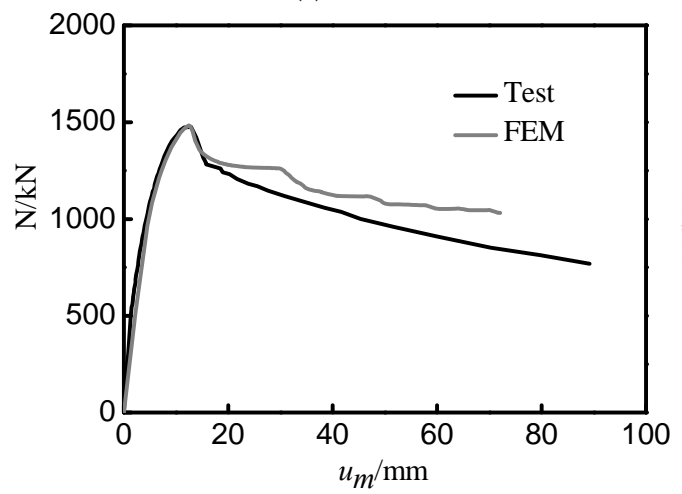

(k) ESF10-5-71

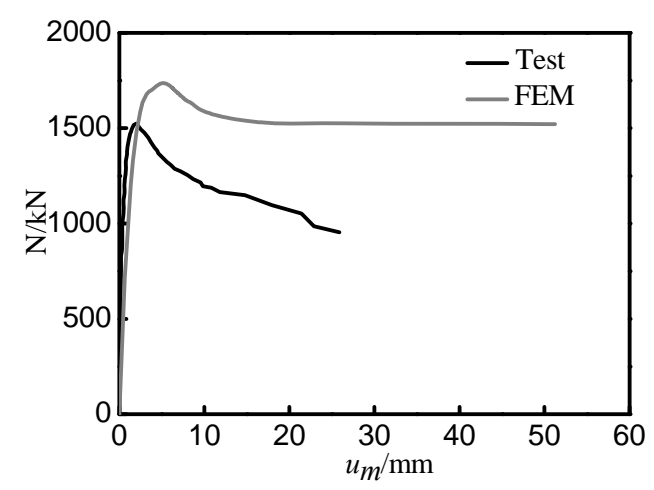

(m) ES4-4-71

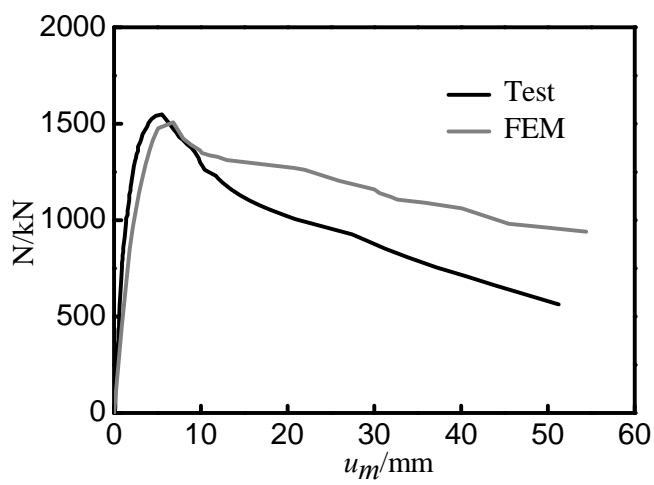

(o) ES6-4-71

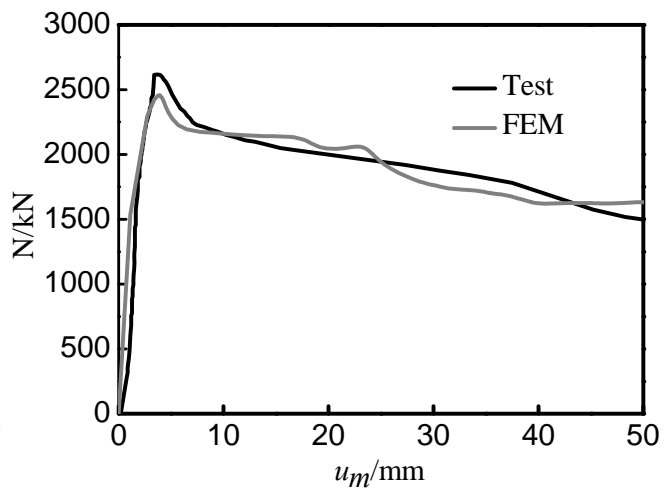

(j) ESF10-5-28

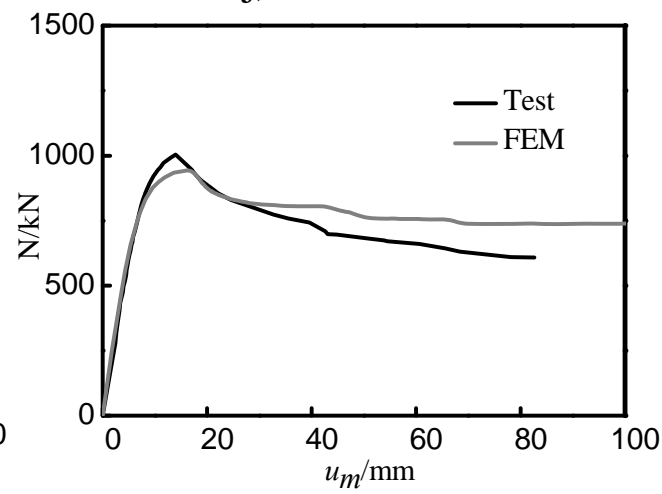

(l) ESF10-5-113

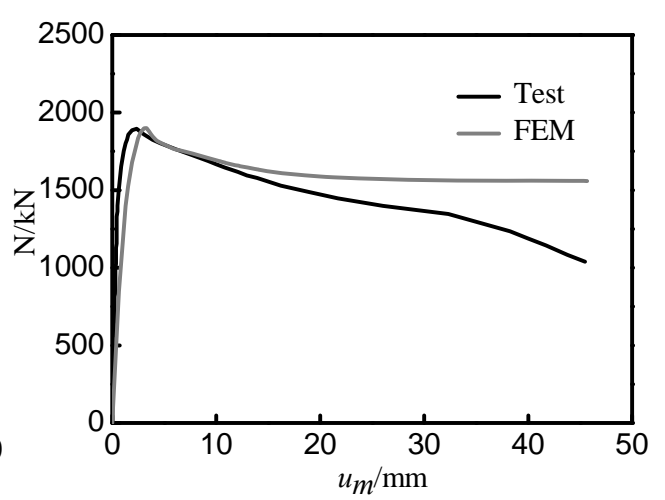

(n) ES4-6-71

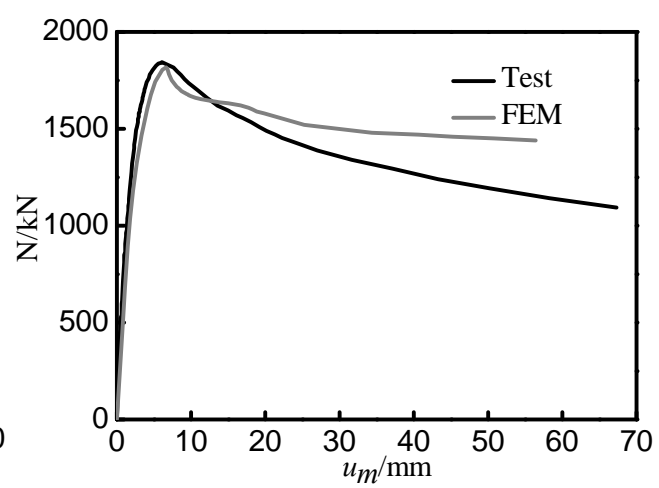

(p) ES6-6-71 


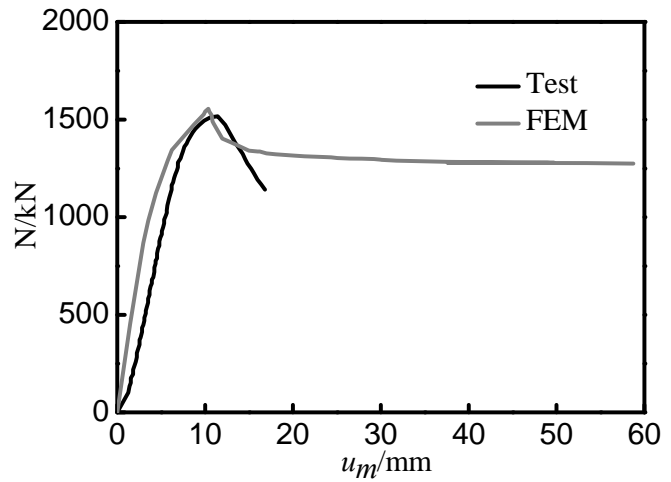

(q) ES8-4-71

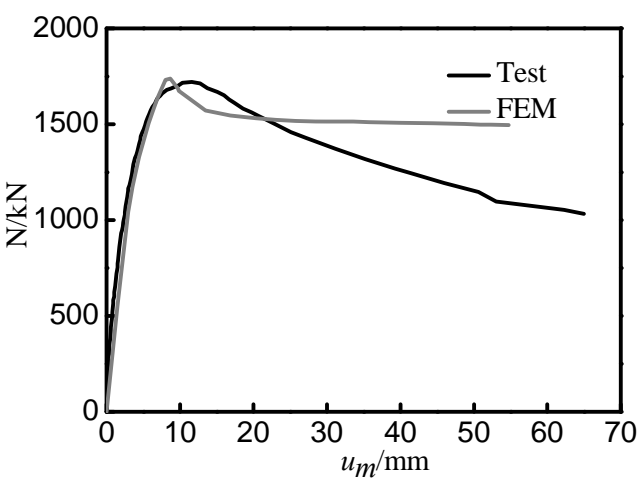

(r) ES8-6-71

Figure 4. Comparisons of Predicted Load Versus Deflection Curves of Columns with Tested Results

\subsubsection{Analysis on Load-deformation Curve}

The typical curve of load versus deflection was calculated and shown in Figures 5. The curve can be divided into four stages.

Elastic stage (OA): As lateral expansion of the steel tube is larger than that of the concrete during the initial loading stage, there is little interaction between the steel tube and the sandwich concrete. The steel and concrete bear the load independently in this stage. The steel is yielded at point A.

Elastic-plastic stage $(\mathrm{AB})$ : In this stage, the crack occurs in the concrete and lateral expansion of the concrete exceeds that of the steel tube. It makes the steel in biaxial stress condition and the concrete in tri-axial stress condition. And the steel tube begins to confine the concrete. The steel tube developes plastic from point $\mathrm{A}$ in the compression zone. As the load increases, the plastic zone expands to the peak point $\mathrm{B}$.

Descent stage (BC): In this stage, load - deflection curve tends to decline after the steel tube has developed plasticity fully. At point $B$, the specimen achieves the ultimate bearing capacity. The bearing capacity lasts for a moment and then the curve goes down quickly. Local buckling of the steel tube on the compression side occurs at the mid height of the specimen. It makes the sandwich concrete lose confinement from steel tube. But the core concrete is still confined by CFRP tube and bear a large proportion of the vertical load. As the deflection reaches a certain value, the bearing capacity begins to descend slowly, and the deflection increase rapidly. The strain of CFRP tube increases until point $\mathrm{C}$.

Descent stage (CD): At point C, the CFRP tube reaches the ultimate strain, the confinement of CFRP tube disappears, and the bearing capacity declines again. Due to the increase of side deflection, the specimens finally quit working owing to unstable failure. 


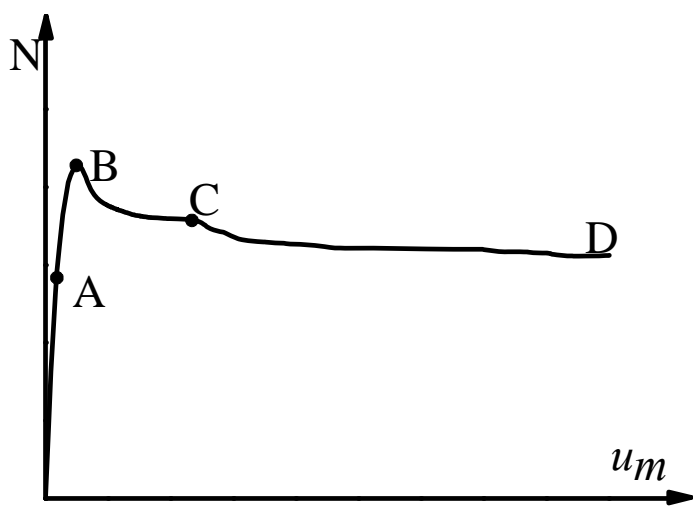

Figure 5. Load (N) to Deflection $\left(u_{m}\right)$ Relations

The concrete stress isoline of mid-height section of specimen ESF4-5-113 is illustrated in Figures 6. The picture of a1, a2 and a3 are stress isolines of sandwich concrete at point $\mathrm{B}, \mathrm{C}, \mathrm{D}$ respectively in Figures 5. The picture of b1, b2 and b3 are stress isolines of core concrete at point $\mathrm{B}, \mathrm{C}, \mathrm{D}$ respectively in the Figures 5 . It can be seen that the tension area expends and compression area reduces with the increasing of the load, and the neutral axis gradually approaches to compression zone from Figures 6. The stress ratio of the compression concrete and the confinement stress of corner concrete increases continuously after the CFRP rupture at point $\mathrm{C}$, which indicates that corner confinement is obvious.

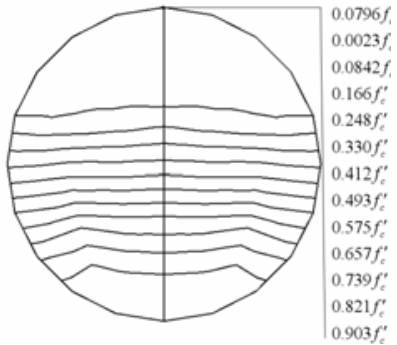

(a1) B

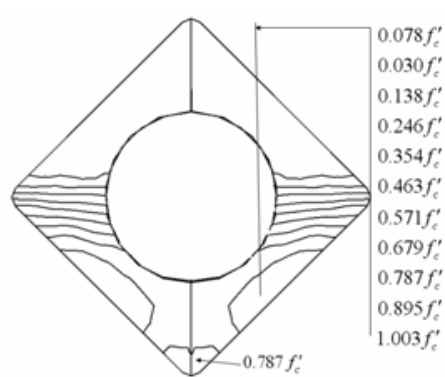

(b1) B

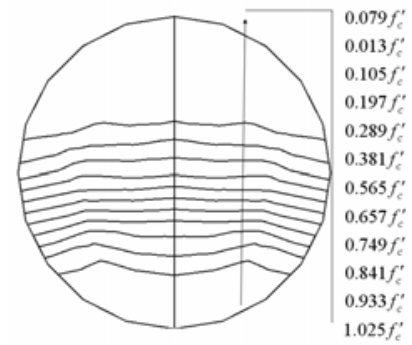

(a2) C

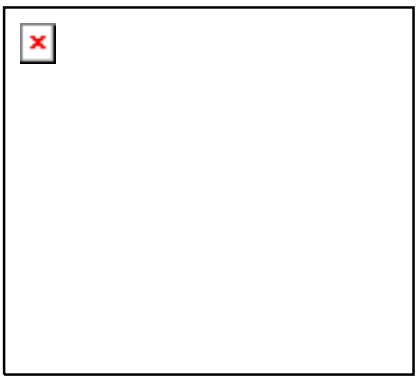

(b2) C

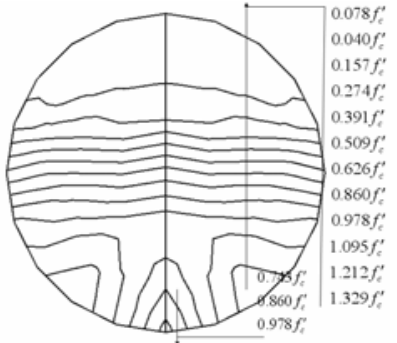

(a3) D

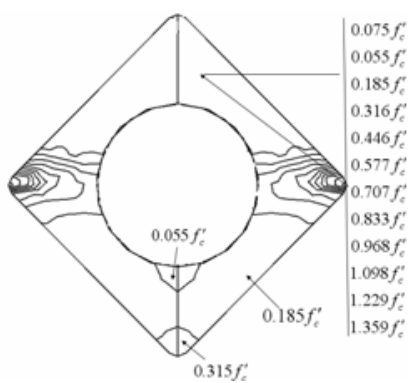

(b3) D

Figure 6. The Longitudinal Stress Isoline in the Core Concrete Section of Specimen ESF4-5-113

The longitudinal stress distribution of CFRP along the length of specimen ESF4-5-113 is illustrated in Figures 7. The pictures of a1, a2, a3 and a4 are longitudinal stress contour at point A, B, C, D respectively in the Figures 5. From Figures 7, the stress of CFRP in the tension zone is smaller than that in the compression zone. The stress increases with the load augmenting from point A to B , and mounts up with the increase of the deflection. 


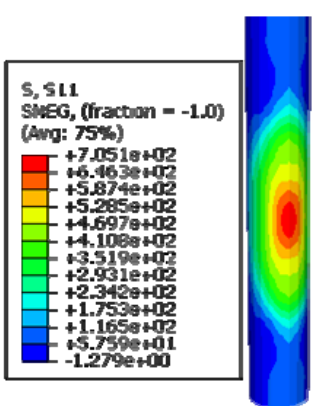

(a1) A

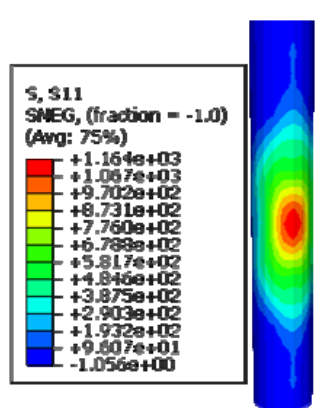

(a2) B

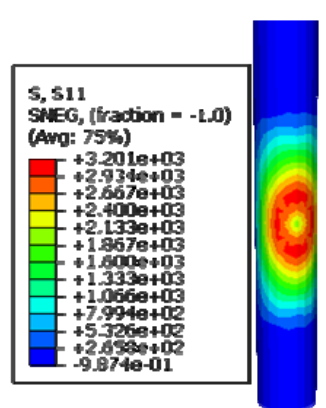

(a3) C

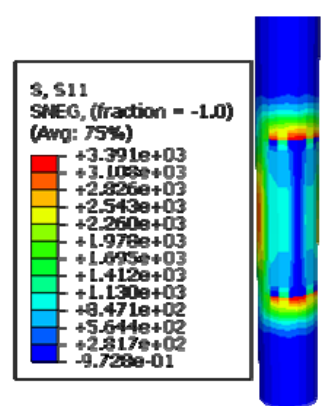

(a4) D

Figure 7. The Longitudinal Stress Distribution of CFRP along the Length

Figures 8 shows the Mises stress distribution of steel tube at mid-height section of specimen ESF4-5-113, at point A, B, C, D respectively in the Figures 5. From (a1), it can be seen that the corner area of HCFSTF steel tube yields earlier than flat area. It is similar to what HCFST does. The difference between the two members is that while the corners of HCFSTF close to the compression zone yield, the compression corners of HCFST yield . The result shows that the confining effect of steel corner area is improved by inner CFRP tube.

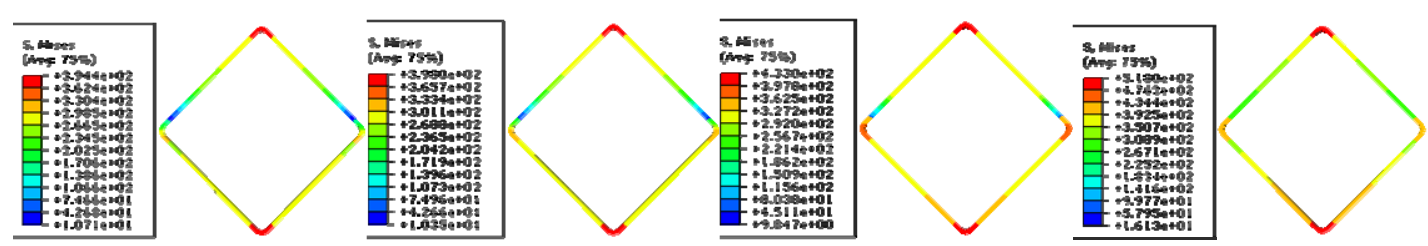

(a1) A

(a2) B

(a3) C

(a3) D

Figure 8. The Longitudinal Mises Stress Distribution of Mid-height Section

The longitudinal plastic strain distribution of sandwich concrete and core concrete along the length of specimen ESF4-5-113 is illustrated in Figures 9 at point B, C, D respectively in the Figures 5. At point $\mathrm{A}$, the specimen is in elastic stage, and the concrete has no plastic strain. With the increasing of deflection, plastic strain occurs at the mid-height and spreads to both ends. And then a plastic strain field develops at compression zone. In addition, the positions where the plastic strain develops of both sandwich and core concrete are at the same location. It indicates that the sandwich and core concrete work well together.

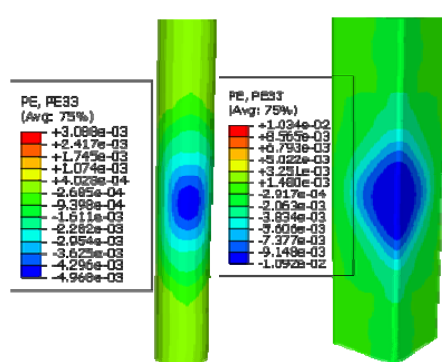

(a1) B

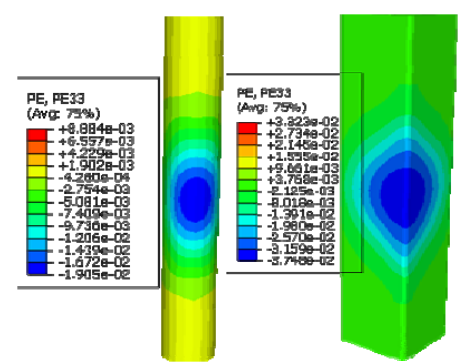

(a2) C

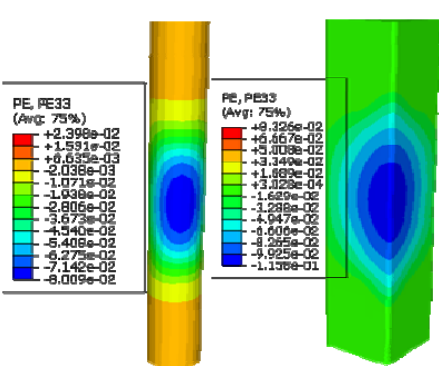

(a3) D

Figure 9. The Longitudinal Strain Distribution of Sandwich and Core Concrete of ESF4-5-113 


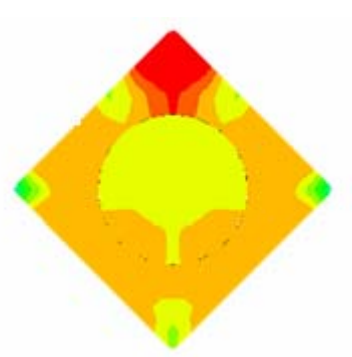

(a) $=28 m m$

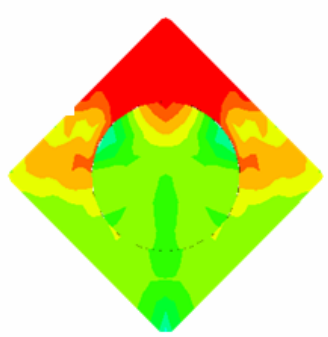

(b)e $=71 \mathrm{~mm}$

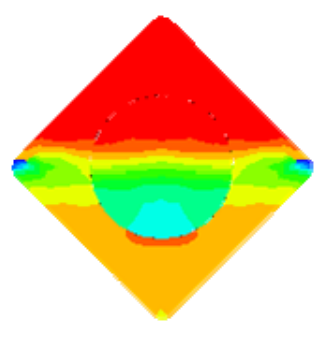

(c) $\mathrm{e}=113 \mathrm{~mm}$

Figure 10. The Longitudinal Stress Distribution in the Concrete Section of ESF4 Series

The concrete stress distribution of mid-height section of HCFSTF specimens at point B with different eccentricity is illustrated in Figures 10. The tension zone area and stress increase with the increasing of eccentricity.

\subsection{Failure Mode of the Specimen}

Figure 11 shows the typical failure modes of HCFSTF and HCFST member subjected to bi-axial eccentric loading. It can be seen from Figure 11 that the failure mode of high strength concrete-filled square steel tube columns with inner CFRP circular tube (HCFSTF) and high strength concrete-filled square steel tube columns (HCFST) are similar . And finally the specimens quit working because of unstable failure.

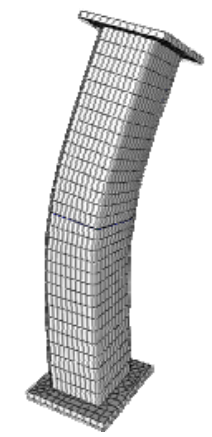

(a) HCFST

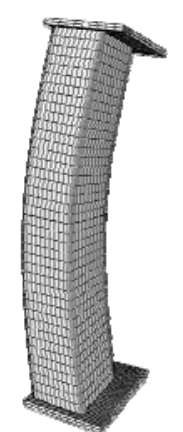

(b) HCFSTF

Figure 11. Typical Failure Mode of HCFSTF and HCFST Columns

Figure 12 is the numerical deflection curves of specimen ESF10-5-113 in the process of loading. It is compared with the ideal half-sine-wave. The vertical coordinate is values of $\mathrm{H} / L$ coincident with different positions at the column. The deflection $u_{\mathrm{m}}$ is calculated by the deflection of two tension sides $\left(u_{m}=\sqrt{u_{x}^{2}+u_{y}^{2}}\right), u_{\mathrm{x}}$ and $u_{\mathrm{y}}$ are the deflections of two tension sides respectively. The deflection curves of numerical results fit well with the ideal half-sine-wave curves. And the smaller the load is, the better the curves fit.

The comparison between the predicted load $(\mathrm{N})$ versus $\left(u_{\mathrm{m}}\right)$ curves of HCFSTF column and HCFST column is shown in Figures 13. The solid lines are the HCFST column, and the dotted lines are HCFSTF column. It can be seen that the ultimate bearing capacities of the two members are proximal. But HCFSTF column seems to have a significant influence on curvature ductility and the load capacity after the peak load. 


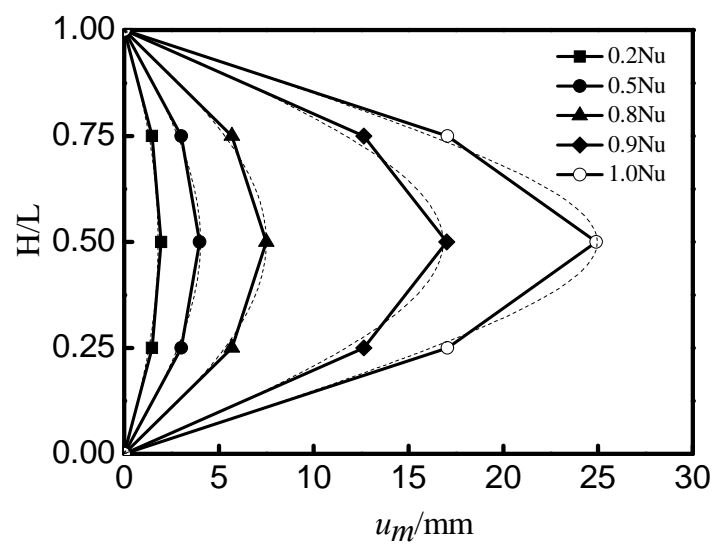

Figure 12. Deflections Curves of Specimen

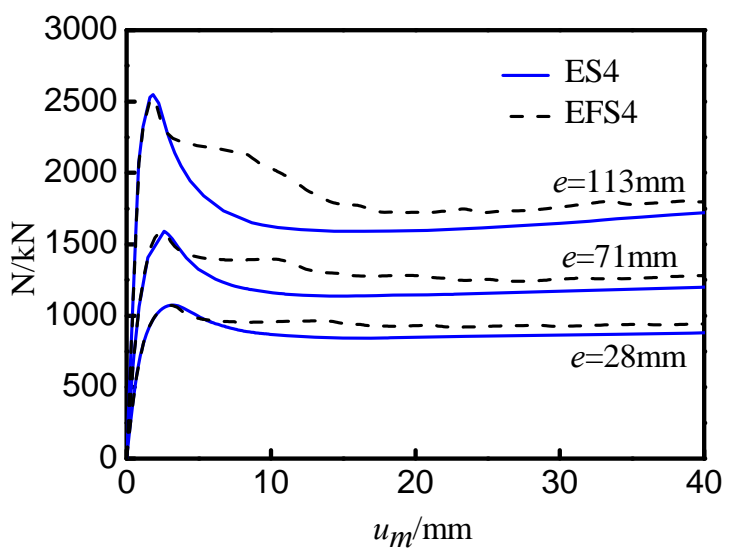

Figure 13. Load-deflections Curves of HCFSTF and HCFST Specimen

\subsection{Parameter Analysis}

\subsubsection{Effect of concrete strength}

Figures 14 shows the $N-M$ interaction curves of HCFSTF members with different concrete strength subjected to bi-axial eccentric loading . The parameters of these examples are: $\mathrm{B}=200 \mathrm{~mm}$ (size of section side for square steel tube,) $f_{\mathrm{y}}=291 \mathrm{Mpa}, \alpha=0.1$, and the eccentric angle is $45^{\circ}$. The values of abscissa $\left(M / M_{u}\right)$ of inflection point on the $N-M$ interaction curve increase with the increasing of concrete strength. The effect of concrete strength on the interaction curve is moderate.

\subsubsection{Effect of steel ratio}

Figures 15 shows the $N-M$ interaction curves of HCFSTF members subjected to bi-axial eccentric loading with different steel ratio. The values of vertical coordinate $\left(N / N_{u}\right)$ and abscissa $\left(M / M_{u}\right)$ of inflection point on the $N-M$ interaction curve increase with the increasing of steel ratio. When the steel ratio changes from $10 \%$ to $15 \%$, the curve changes obviously.

\subsubsection{Effect of steel yield strength}

Figures 16 shows the $N-M$ interaction curves of HCFSTF members subjected to bi-axial eccentric loading with different yield strength of steel. With the increasing of yield strength, the $N / N_{u}$ increases, but $M / M_{u}$ decreases. In addition, when yield strength changes from Q234 to Q345, the curves are much different.

\subsubsection{Effect of slenderness ratio}

Figures 17 shows the $N-M$ interaction curves of HCFSTF members subjected to bi-axial eccentric loading with different slenderness ratio. The slenderness ratio has a great influence on the interaction curves. When the slenderness ratio is small, the interaction curves show parabola model. With the increasing of the slenderness ratio, the ultimate bearing capacity decreases. And the $N-M$ interaction curves change from the parabola model to linear model. 


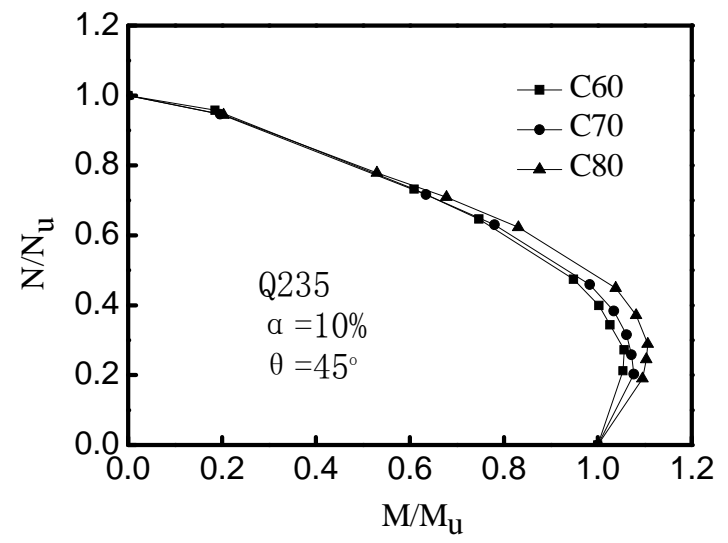

Figure 14. Effect of Concrete Strength

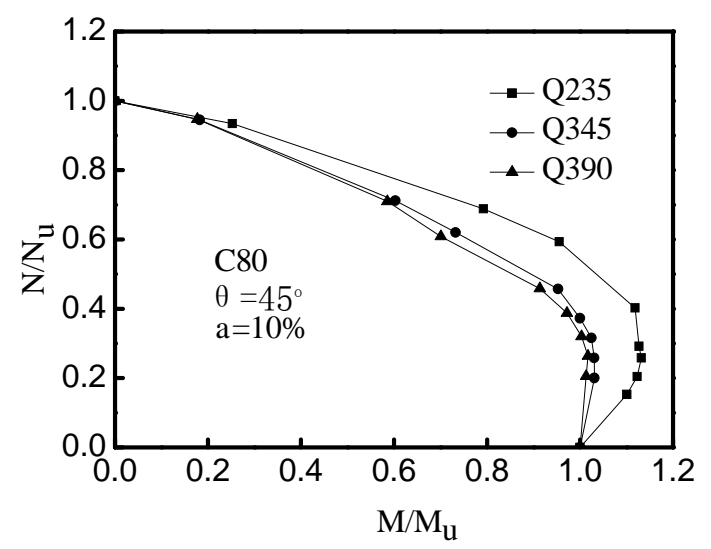

Figure 16. Effect of Steel Yield Strength

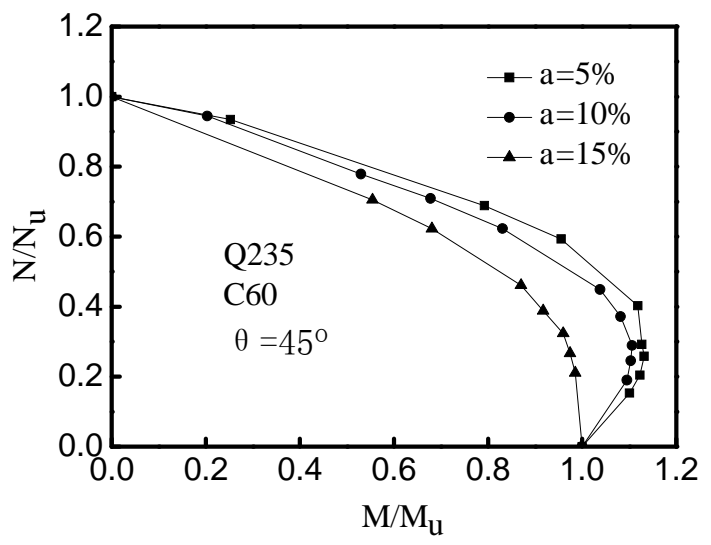

Figure 15. Effect of Steel Ratio

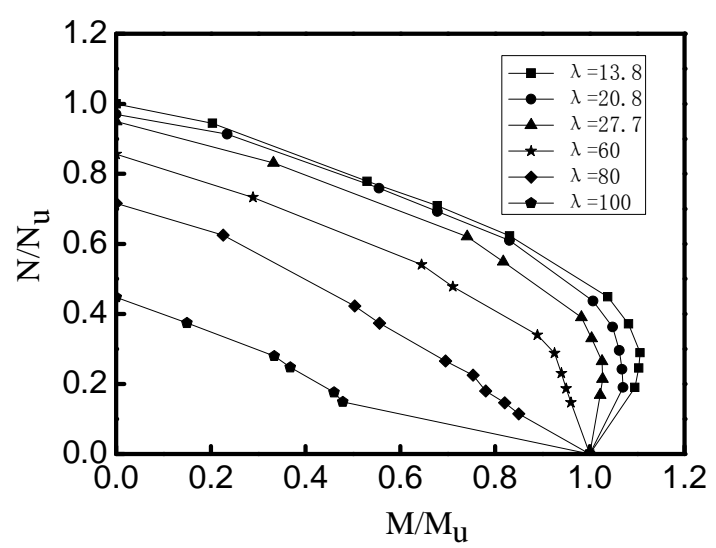

Figure 17. Effect of Slenderness Ratio

\section{SIMPLIFIED CALCULATION ON BEARING CAPACITY}

The parameter analysis results indicate that the factors mainly affecting the $N$ - $M$ interaction curves of HCFSTF members subjected to bi-axial eccentric loading are as follows: yield strength of steel, concrete strength, steel ratio and slenderness ratio. Figures 18 is the typical $N-M$ interaction curve. The equilibrium point A of the curve is similar to that of HCFST member. The vertical coordinate and abscissa of point $\mathrm{A}$ is defined to be $\zeta_{0}$ and $\eta_{0}$, respectively. Figures 14 shows that point A moves to the exterior and the value of $\zeta_{0}$ and $\eta_{0}$ increases with the increasing of concrete strength. Figures 15 and 16 show that point A moves to the interior and the values of $\zeta_{0}$ and $\eta_{0}$ decrease with the increasing of steel yield strength and steel ratio. It is because that the bigger the yielding strength of steel and steel ratio are, the more contribution steel tube makes in the composite column. On the contrary, the higher strength of concrete is, the more contribution concrete makes.

The vertical coordinate $\left(\zeta_{0}\right)$ and abscissa $\left(\eta_{0}\right)$ of the equilibrium point A can be expressed as function of the composite confinement factor $(\xi)$. Based on the regression analysis on a great deal of computed results, the formula to calculate $\zeta_{0}$ and $\eta_{0}$ are given as follows:

$$
\begin{aligned}
& \xi_{0}=1.03+0.005 \xi^{-2.9} \\
& \eta_{0}= \begin{cases}0.5-0.335 \xi & (\xi \leq 0.55) \\
0.1+0.127 \xi^{-0.82} & (\xi>0.55)\end{cases}
\end{aligned}
$$




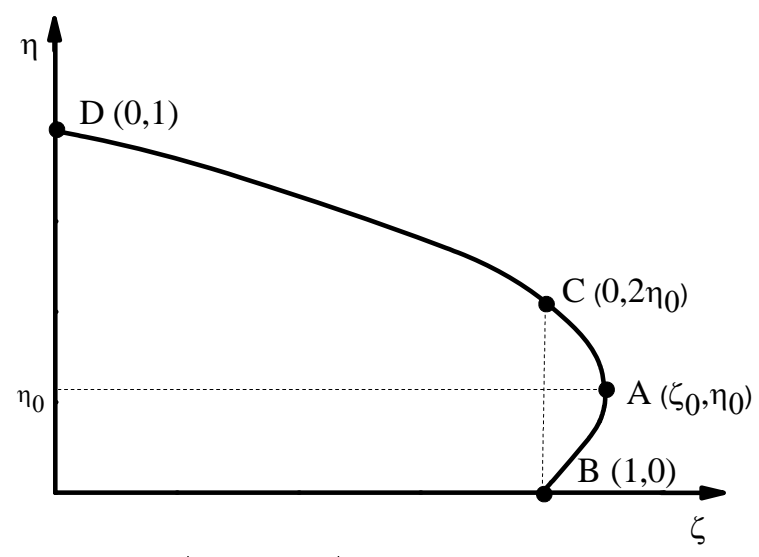

Figure 18. Typical $N / N_{\mathrm{u}}-M / M_{\mathrm{u}}$ Interaction Curve of HCFSTF

Where $\xi$ is confinement factor, which can be obtained as follows:

$\xi=\xi_{s}+\theta \xi_{c f r p}$

Where $\xi_{s}$ is the confinement factor of the steel tube $\xi_{s}=A_{s} f_{s y} / A_{c 1} f_{c k}$, $A_{s}$ is the cross-sectional area of the steel tube, $A_{c 1}$ is the cross-sectional area of the concrete, $f_{s y}$ is the yield stress of the steel tube, and $f_{c k}$ is the compression strength of concrete; $\xi_{c f r p}$ is the confinement factor of the inner CFRP tube $\xi_{c f r p}=A_{c f r p} f_{c f r p} / A_{c 2} f_{c k}, A_{c f r p}$ is the cross-sectional area of the CFRP tube, $A_{c 2}$ is the cross-sectional area of the core concrete, $f_{\text {cfrp }}$ is the ultimate stress of the CFRP tube. $\gamma$ is the relative confinement factor $\gamma=\xi_{\text {cfrp }} / \xi_{s} ; \theta=0.7$.

what is analyzed above shows that the mechanical behavior of high strength concrete-filled square steel tube slender columns with inner CFRP circular tube (HCFSTF) and high strength concrete-filled square steel tube slender columns (HCFST) are similar. The interaction equations of $N / N_{u}-M / M_{u}$ for HCFST [23] are referred, and the interaction equations of $N / N_{u}-M / M_{u}$ for HCFSTF can be divided into two parts, which are expressed as follows:

1. For $N / N_{u} \geq 2 \eta_{0}$

$\frac{N}{N_{u}}+a\left(\frac{M}{M_{u}}\right)=1$

2. For $N / N_{u}<2 \eta_{0}$

$-b\left(\frac{N}{N_{u}}\right)^{2}-c\left(\frac{N}{N_{u}}\right)+\left(\frac{M}{M_{u}}\right)=1$

Where $a=1-2 \eta_{o}, b=\frac{1-\zeta_{o}}{\eta_{o}^{2}}, c=\frac{2\left(\zeta_{o}-1\right)}{\eta_{o}}$.

Taking into account the slenderness effect, the interaction equations of $N / N_{u}-M / M_{u}$ for HCFSTF can be expressed as follows: 
1. For $N / N_{u} \geq \varphi_{x y}^{3} 2 \eta_{0}$,

$\frac{N}{\varphi_{x y} N_{u}}+\frac{a}{d}\left[\left(\frac{M_{x}}{M_{u x}}\right)^{1.8}+\left(\frac{M_{y}}{M_{u y}}\right)^{1.8}\right]^{1 / 1.8} \leq 1$

2. For $N / N_{u}<2 \varphi_{x y}^{3} \eta_{0}$,

$-b \frac{N^{2}}{N_{u}^{2}}-c \frac{N}{N_{u}}+\frac{1}{d}\left[\left(\frac{M_{x}}{M_{u x}}\right)^{1.8}+\left(\frac{M_{y}}{M_{u y}}\right)^{1.8}\right]^{1 / 1.8} \leq 1$

Where $N_{u}$ is ultimate axial compressive strength of HCFSTF; $\varphi_{x y}$ is stability coefficient of CFST under bi-axial eccentric loading; $M_{x}$ and $M_{y}$ are moments along the x-axis and y-axis respectively, which are given by $M_{x}=N e_{x}$ and $M_{y}=N e_{y} ; M_{u x}$ and $M_{u y}$ are flexural bearing capacity along the x-axis and y-axis respectively; Where a,b,c,d is calculating coefficient, and $1 / \mathrm{d}$ is amplification factor of the moment considering the second-order effect. The calculations in details on these parameters are given by references [19] and [23].

The stability bearing capacity of experimental specimen was calculated with the above simplified formula. Table 1 shows calculating results $\left(N_{c 2}\right)$ and measured values $\left(N_{e}\right)$. The ratio of $N_{c 2} / N_{e}$ is listed in Table 1, which average is 1.027 . The standard deviation is 0.073 . The calculating results agree well with test data, so the simplified formula can be applied to calculating the bearing capacity of HCFSTF within the parameters of this test.

\section{CONLUSIONS}

(1) An FEA modeling developed through the ABAQUS/Standard solver is used to study the flexural performance of HCFSTF columns under bi-axial eccentric loading. The predicted load versus deflection curves and ultimate bearing capacity for composite columns have been found in good agreement with experimental results.

(2) The parametric studies indicate that the major factors affecting the $N / N_{u}-M / M_{u}$ interaction curves of HCFSTF members subjected to bi-axial eccentric loading are steel yield strength, concrete strength, steel ratio and slenderness ratio.

(3) Based on the experimental and FEA results, a simplified formula for the calculation of the bearing capacity of the composite column is proposed. The simplified formula is applied to calculate the bearing capacity of the experimental specimens. And the calculation results agree well with test data. So the simplified formula can be referred to calculate the bearing capacity of HCFSTF within the parameters of this test.

\section{ACKNOWLEDGEMENTS}

This project was supported by National Science Foundation of China (50678106), Shenyang Talent Development Fund (2009140403038), Liaoning BaiQianWan Talents Program(2010921001), Liaoning Talents Program(LR2011014) and Technology Development Program of Ministry of Housing and Urban-Rural Development (2011-k3-23). 


\section{REFERENCES}

[1] Fan, H., Li, Q.S., Tuan, A.Y. and Xu, L.H., "Seismic Analysis of the World's Tallest Building”, Journal of Constructional Steel Research, 2009, Vol. 65, No. 5, pp. 1206-1215.

[2] Liu, D.L., Gho, W.M. and Yuan, J., "Ultimate Capacity of High Strength Rectangular Concrete-filled Steel Hollow Section Stub Columns", Journal of Constructional Steel Research, 2003, Vol. 59, No. 12, pp. 1499-1515.

[3] Liu, D.L., "Behaviour of High Strength Rectangular Concrete-filled Steel Hollow Section Columns under Eccentric Loading”, Thin-Walled Structures, 2004, Vol. 42, No.12, pp. 1631-1644.

[4] Liu, D.L., "Behaviour of Eccentrically Loaded High-strength Rectangular Concrete-filled Steel Tubular Columns”, Journal of Constructional Steel Research, 2006, Vol. 62, No. 8, pp. 839-846.

[5] Ellobody, E. and Young, B., "Design and Behavior of Concrete-filled Cold-formed Stainless Steel Tube Columns”, Engineering Structures, 2006, Vol. 28, No. 5, pp. 716-728.

[6] Young, B. and Ellobody, E., "Experimental Investigation of Concrete-filled Cold-formed High Strength Stainless Steel Tube Columns”, Journal of Constructional Steel Research, 2006, Vol. 62, No. 5, pp. 484-492.

[7] Lu, F.W., Li, S.P. and Sun, G.J., "A Study on the Behavior of Eccentrically Compressed Square Concrete-filled Steel Tube Columns”, Journal of Constructional Steel Research, 2007, Vol. 63, No. 7, pp. 941-948.

[8] Chitawadagi, M.V., Narasimhan, M.C. and Kulkarni, S.M., “Axial Capacity of Rectangular Concrete-filled Steel Tube Columns-DOE Approach”, Construction and Building Materials, 2010, Vol. 24, No. 4, pp. 585-595.

[9] Han, L.H., Zhao, X.L. and Tao, Z., "Tests and Mechanics Model for Concrete-filled SHS Stub Columns”, Steel and Composite Structures, 2001,Vol. 1, No. 1, pp. 51-74.

[10] Han, L.H., “Tests on Stub Columns of Concrete-filled RHS Sections”, Journal of Constructional Steel Research, 2002, Vol. 58, No. 3, pp. 353-372.

[11] Uy, B., "Strength of Short Concrete Filled High Strength Steel Box Columns", Journal of Constructional Steel Research, 2001, Vol. 57, No. 2, pp. 113-134.

[12] Mursi, M. and Uy, B., "Strength of Concrete Filled Steel Box Columns Incorporating Interaction Buckling”, Journal of Structural Engineering, 2003, Vol. 129, No. 5, pp. 626-639.

[13] Mursi, M. and Uy, B., "Strength of Slender Concrete Filled High Strength Steel Box Columns”, Journal of Constructional Steel Research, 2004, Vol. 60, No. 12, pp. 1825-1848.

[14] Mursi, M, and Uy, B., "Behavior and Design of Fabricated High Strength Steel Columns Subjected to Biaxial Bending, Part 1: Experiments", Journal of Advanced Steel Construction, Hong Kong Institute of Steel Construction, 2006, Vol. 2, No. 4, pp. 286-315.

[15] Mursi, M. and Uy, B., "Behaviour and Design of Fabricated High Strength Steel Columns Subjected to Biaxial Bending, Part 2: Analysis and Design Codes”, Journal of Advanced Steel Construction, Hong Kong Institute of Steel Construction, 2006, Vol. 2, No. 4, pp. 316-354.

[16] Liu, J.P., Zhang, S.M. and Guo, L.H., "Behavior of Concrete-filled Steel RHS Subjected to Biaxial Eccentric Loading”, Journal of Harbin Institute of Technology, 2006, Vol. 38, No. 5, pp. 712-714.

[17] Tian, H., Guo, L.H. and Zhang, S.M., "Behavior of High-strength Concrete-filled RHS Steel Tubular Members Subjected to Axial Combined with Bi-axial Bending”, Journal of Harbin Institute of Technology, 2007, Vol. 39, No. 12, pp. 1854-1858. 
[18] Tokgoz, S. and Dundar, C., "Experimental Study on Steel Tubular Columns In-filled with Plain and Steel Fiber Reinforced Concrete”, Thin Walled Structure, 2010, Vol. 48, No. 6, pp. 414-422.

[19] Yang, Z.J, "Behavior of High Strength Concrete Filled Square Steel Tubes Slender High Columns with Inner CFRP Circular Tube under Bi-axial Eccentric Loading, Master's Thesis”, Shenyang Jianzhu University, 2010.

[20] Abdel, R.N. and Sivakumaran, K.S., "Material Properties Models for Analysis of Cold-formed Steel Members”, Journal of Structural Engineering, 1997, Vol. 123, No. 9, pp. 113-1143.

[21] Han, L.H., Yao, G.H. and Tao, Z., "Performance of Concrete-filled Thin-walled Steel Tubes under Pure Torsion”, Thin-Walled Structures, 2007, Vol. 45, No. 1, pp. 24-36.

[22] Jiang, J.J., Lu, X.Z. and Ye, L.P., "Finite Element Analysis of Concrete Structures", Tsinghua University Press, 2005.

[23] Han, L.H., "Concrete-Filled Steel Tube Structure-Theory and Practice (Second Edition)”, Science Press, 2008. 